\title{
E. Feteris, B. Garssen and F. Snoeck Henkemans (eds): Keeping in Touch with Pragma-Dialectics. In Honor of Frans H. van Eemeren
}

John Benjamins, Amsterdam, Philadelphia, 2011

\author{
Paul van den Hoven
}

Published online: 28 June 2012

(C) The Author(s) 2012. This article is published with open access at Springerlink.com

Keeping in touch with pragma-dialectics contains 17 contributions written for Frans van Eemeren on the occasion of his retirement. Publications 'in honor of' are always entertaining for all who are sympathetic to the laureate (let us consider a retirement as a tribute to a long and very fruitful career) but may lack a clear focus that is shared by the majority of the contributors, may lack the weight to be considered as a substantial contribution to the discipline. The somewhat 'empty' title of this volume may support that expectation. That would be a pity! Keeping in touch with pragmadialectics could have carried the much too lengthy subtitle: Exploring the expressiveness and the limits of the extended pragma-dialectic argument theory; a meta-dialectical exercise.

The contributions in the book are all written by a team of authors, mostly two, one being a (former) PhD-student and/or staff member of Frans van Eemeren, one being a highly distinguished colleague with his or her roots in any other relevant tradition than the pragma-dialectical theory. Due to the fact that all the teams have very experienced, widely-read members with often pronounced opinions, and due to the fact that the theoretical framework that all contributions want to connect to is explicit and comprehensive, the book has become an important help to those who want to think through the implications of the theoretical extensions of the pragmadialectical standard theory. These theoretical extensions have been most elaborately presented in Van Eemeren's (2010) book Strategic maneuvering in argumentative discourse (Amsterdam: John Benjamins).

The extension of the theory concerns mainly the strategic maneuvering between on the one hand the dialectical reasonableness that participants in argumentative discussions basically orient upon, and on the other hand rhetorical effectiveness, the aim to 'win' the discussion in the eyes of a relevant audience. This theoretical

P. van den Hoven $(\bowtie)$

Utrecht Institute of Linguistics, Utrecht University, Muntstraat 2a, 3512EV Utrecht,

The Netherlands

e-mail: p.vandenhoven@uu.nl 
extension raises a lot of challenging analytical issues, theoretical issues and even philosophical issues to consider. Most of the contributions deal with one or more of these issues.

To give an impression of the value of Keeping in touch with pragma-dialectics for those dealing with such issues I quote from the eloquent first section of the contribution of Dima Mohammed and David Zarefsky about the pragma-dialectical analysis of rhetorical texts.

Pragma-dialectics examines interactive arguments, those in which (usually) two arguers advance, defend or challenge standpoints in a sequential fashion, through which their moves can be identified and scrutinized. And the analysis assumes that the arguers' goal is to resolve disagreements in a reasoned manner. [...] Whereas the commitments of dialogue partners either are known in advance or can be probed through the steps in exchange, in many situations an audience's commitments can only be assumed or guessed at. Since audiences are seldom homogeneous, different members may have different starting points; [...] And [...] an arguer often addresses multiple audiences simultaneously. [...] Whether the argument should be evaluated in relation to the addressed or to the intended audience is often unclear (pp. 89-90).

The authors elaborate on these complications, using Barack Obama's Cairo speech as an example. Obviously this is informative for everyone who-as I do-tries to model the exact relations between the (dialectical) analytical concepts of antagonist and reasonable judge in the theoretical definition of argumentation (Van Eemeren 2010, p. 29) and the (rhetorical) concept of an audience (or several audiences). Of course, the audience of the participant who fulfills the dialectical role of protagonist may coincide with his antagonist and, vice versa, the audience of the participant who fulfills the dialectical role of antagonist may coincide with his protagonist. But the audience can also fill in the abstract analytical role of the reasonable judge. Or the 'discussion' — as Mohammed and Zarefsky emphasize — can be performed in the presence of several audiences that are relevant for one of the participants. This is the case when a president speeches in front of a live audience and cameras of several networks, addressing a number of controversial issues. Many of the contributions in Keeping in touch with pragma-dialectics deal with this complication, explicitly of more implicitly, but always in way that helps the reader to articulate his or her own contemplations.

Another analytical and theoretical issue is whether the extension of the theory implies that more discourse phenomena are considered argumentation now than before or not. The pragma-dialectical theoretical criterion to consider communicative acts as argumentative is that they are part of an attempt to resolve a difference of opinion in a reasonable way. The most liberal formulation that I have found is that "arguers [...] have to maintain the image of people who play the resolution game by the rules" (Van Eemeren 2010, p. 42); the theoretical definition (Van Eemeren 2010, p. 29) sounds more restrictive. To explore this issue the contribution of Trudy Govier and Henrike Jansen is helpful. They continue a theoretical debate raised by Christopher Oldenburg and the late Michael Leff during OSSA 2007 whether telling an anecdote can be considered bringing forward an argument, and if 
so, how to evaluate such an argument. When Oldenburg and Leff claim that an anecdote can create a "holistic insight that reaches beyond the possibilities of propositional argument" (quote on p. 78), are we still in touch with pragmadialectics then? And if so, are we confronted with an acceptable way of strategic maneuvering - meaning that the anecdote telling protagonist commits himself to the dialectical obligations? What in that case are these obligations and what is the rhetorical force of this 'presentational device'? Or is presenting an anecdote always a 'derailment'? Govier and Jansen address all these questions explicitly. In several of the other contributions (for example Bart Garssen and Manfred Kienpointner of figurative analogy, Jeanne Fahnestock and Yvon Tonnard on amplification) mutatis mutandis similar questions are discussed.

The reverse of the issue whether the extension of the theory implies that more discourse phenomena are considered argumentation, is the issue whether more discourse approaches can be related to extended pragma-dialectic theory? Wellknown is the early (1993) attempt of Van Eemeren, Grootendorst, Jackson and Jacobs to relate the pragma-dialectical theory to a discourse analytical approach. In Keeping in touch with pragma-dialectics Constanza Ihnen and John E. Richardson raise the question if and how the extended pragma-dialectics can be combined with Critical Discourse Analysis. One may be interested in that question as such, but more interesting are the considerations what divides both approaches and where they converge.

Issues that directly relate to the basic concept of reasonableness in relation to the (empirical) concept of effectiveness are part of the philosophical component of the pragma-dialectical theory. Van Eemeren states (2010, p. 41): "More often than not argumentative discourse that may be considered reasonable in a critical perspective will also be effective in an empirical perspective". I tend to say, when the dialectical roles and the rhetorical roles coincide, that must be the case. What can be more convincing then a clear and explicit demonstration that a standpoint does or does not follow from a set of concessions, according to a set of starting points agreed upon? However, when several audiences are involved that are certainly not bound to play a role as a reasonable judge, but that participate otherwise, probably differing in starting points, then it really becomes a complicated issue how to reconstruct these complicated situations as a set of discussions. In that case it becomes also a very complicated task to determine and evaluate the strategies employed by a participant to address all these parties most effectively. Several contributions deal with such complicated situations and present actual examples of argumentative discourse; inevitably in these chapters the question is raised what forms of maneuvering are acceptable, what needs to count as a derailment.

A festschrift runs the risk of not being noticed as an important contribution to the academic debate. Keeping in touch with pragma-dialectic is published on the moment that a major theoretical amendment has been made. The book is seriously co-authored by many of the 'celebrities' in the field. Keeping in touch with pragmadialectic should not meet that 'festschrift fate'. It deserves much more and should be considered as a substantial contribution to the discipline. 
Open Access This article is distributed under the terms of the Creative Commons Attribution License which permits any use, distribution, and reproduction in any medium, provided the original author(s) and the source are credited.

\section{References}

van Eemeren, F.H. 2010. Strategic maneuvering in argumentative discourse. Amsterdam: John Benjamins.

van Eemeren, F.H., R. Grootendorst, S. Jackson, and S. Jacobs. 1993. Reconstructing argumentative discourse. Tuscaloosa, London: The University of Alabama Press. 